\title{
GASTROINTESTINAL FISTULAE
}

\section{Pancreatic surgical complications - the case for prophylaxis}

\author{
C Gouillat, J-F Gigot
}

Gut 2002;49(Suppl IV):iv29-iv35

See end of article for authors' affiliations

Correspondence to: C Gouillat, Department of Chirurgie, Hôtel Dieu,

1 Place de l'Hôpital, 69288 Lyon, Cedex 02, France;

christian.gouillat@chu.lyon.fr

Accepted for publication 4 June 2001
Pancreaticoduodenectomy (Whipple's procedure) represents a considerable surgical challenge. Postoperative complications are common and typically related to leakage of pancreatic exocrine secretions following anastomosis failure. Pancreatic proteases and lipase leaking from the organ remnant attack the surrounding tissue, potentially leading to severe inflammation, tissue necrosis, and fistula formation. In addition, the soft consistency of the normal pancreas can lead to difficulties in manipulating the organ and reduce the integrity of sutures. Pancreatic fistula is the most serious postoperative complication and especially common following resectional surgery for malignant disease. Through prophylactic inhibition of digestive secretions, it should be possible to reduce postoperative morbidity after pancreatic surgery. One such inhibitor is somatostatin-14, an endogenous peptide hormone with pronounced effects on secretion of pancreatic enzymes and hormones, gastrointestinal secretions, and pancreatic blood flow, all of which may decrease the risk of postoperative complications. A limited number of randomised controlled trials have investigated prophylactic administration of somatostatin-14 and the synthetic somatostatin analogue octreotide in reducing complications following pancreatic surgery. While the majority of studies with octreotide demonstrated a significant reduction in the overall complication rate, the benefits appeared less marked in relation to events specifically related to pancreatic secretion. However, preliminary results from a limited number of trials with somatostatin-14, administered as a continuous intravenous infusion, suggest that prophylactic pharmacotherapy produces a significant decrease in fistula formation and secretion related events after pancreaticoduodenectomy. Due to these promising data, further investigation of the role of somatostatin-14 prophylaxis in pancreatic surgery is warranted in large well controlled trials.
$A^{a}$ dvances in surgical techniques and progress in intensive care over recent years have led to an increase in the frequency of pancreatic surgery. Furthermore, improved diagnostic capabilities have also resulted in more referrals for surgery, including many older patients and those with severe disease requiring more complex treatment. Despite a reduction in the occurrence of postoperative complications, morbidity and mortality following pancreatic surgery remain as high as $30-40 \%$ and $3-10 \%$, respectively. ${ }^{1-3}$ Complications following pancreatic surgery are numerous and can be classified as localised or general events. A meta-analysis of complication rates in placebo groups of randomised multicentre trials following pancreatic resection has revealed the relative incidence of individual events, detailed in table $1 .{ }^{4}$ It is clear that localised postoperative complications are most prevalent, particularly pancreatic fistulae, from which close to $25 \%$ of patients undergoing surgery may suffer.

Because of the high prevalence of complications following surgery, especially those localised to the peripancreatic region, preventive treatment may be useful in reducing postoperative morbidity. This article aims to discuss the benefits of prophylactic therapy in patients undergoing pancreatic surgery and critically review the evidence published in the clinical setting.

\section{TECHNICAL DEMANDS IN PANCREATIC SURGERY}

Pancreatic surgery is technically demanding due to the physiological function and anatomical nature of the pancreas, and the close proximity of coeliac and mesenteric vascular systems. Pancreaticoduodenectomy (Whipple's procedure)

Abbreviations: CT, computed tomography; SSTR, somatostatin receptor. represents a serious risk as surgery radically alters the anatomical organisation of the pancreas and intestines, allowing inappropriate contact between pancreatic juice and intestinal activating enzymes. Pancreatic exocrine secretions leaking from the remnant of the organ have the potential to cause serious complications. Generally, this process leads to fistula formation with various septic sequelae, including septic shock, life threatening haemorrhage, and multiorgan failure. The active enzymes can digest the surrounding tissues causing severe inflammation and liquefaction necrosis within the pancreas, the peripancreatic region, or the free abdominal cavity. In addition, the soft consistency of the normal pancreas can lead to difficulties in manipulating the organ and also reduce the integrity of sutures. The combination of pancreatic consistency and exocrine secretions make effective anastomosis between the pancreatic remnant and the stomach or jejunum difficult to achieve and potentially prone to failure, leading to serious complications.

Table 1 Incidence of complications following pancreatic resectional surgery in the absence of any preventative treatment-placebo groups from randomised multicentre trials ${ }^{4}$

\begin{tabular}{lcll}
\hline $\begin{array}{l}\text { Localised } \\
\text { complications }\end{array}$ & $\begin{array}{l}\text { Incidence } \\
(\%)\end{array}$ & $\begin{array}{l}\text { General } \\
\text { complications }\end{array}$ & $\begin{array}{l}\text { Incidence } \\
(\%)\end{array}$ \\
\hline Pancreatic fistula & 23.4 & Sepsis & 3.6 \\
Fluid collection & 8.8 & Respiratory failure & 3.3 \\
Anastomosis leakage & 4.0 & Death & 3.3 \\
Bleeding & 4.3 & Shock & 2.4 \\
Abscess & 3.1 & Renal failure & 1.5 \\
Postoperative pancreatitis & 2.9 & & \\
\hline
\end{tabular}


Risk factors associated with postoperative complications The major importance of pancreatic exocrine secretion in the high prevalence of postoperative complications is now well established. The incidence of pancreatic fistulae and/or pancreatic anastomotic leakage after pancreaticoduodenectomy has been reported to be $8-19 \% .^{5}$ Once anastomotic leakage occurs, the associated mortality rate is very high $(8-40 \%) .{ }^{6}$ The main predisposing factor of pancreatic fistulae formation is a soft pancreatic parenchyma. ${ }^{7}$ Patients with a parenchyma of soft to intermediate consistency produce a larger amount of pancreatic juice and have a higher risk of pancreatic leakage than those with a hard consistency. Additional risk factors include whether surgery is performed for chronic pancreatitis or tumours, the site of the tumour, the surgical technique used and, potentially, nutritional status, age, and general health of the patient. ${ }^{2}$

In recent years, Whipple's procedure has been used increasingly to resect a variety of malignant and benign diseases of the pancreas and periampullary region. A large scale meta-analysis of 2684 cases of Whipple's procedure performed between 1980 and 1990 emphasised the importance of the presence and site of neoplasms and the morphology of the pancreas on the incidence of complications. ${ }^{2}$ In this study, the rate of fistula formation following surgery for various conditions was reported as 33\% in patients with biliary cancer, $15 \%$ with ampullary cancer, $12 \%$ with pancreatic cancer, and $5 \%$ with chronic pancreatitis, with subsequent mortality rates of $70 \%, 27 \%, 31 \%$, and $9 \%$, respectively. The relatively low prevalence of complications following surgery for chronic pancreatitis is related to the pathophysiology of the condition. Changes in the pancreas during the late stages of the condition lead to a reduced capacity for both exocrine and endocrine secretion and the associated degeneration of the acinar tissue results in a more fibrous consistency. ${ }^{8}$ The combination of these factors is thought to account for the decrease in anastomotic failure following surgery for chronic pancreatitis, and the subsequent significant decrease in the rate of fistula formation in comparison with malignant disease. ${ }^{2}$

With regard to the influence of age, the trend is less apparent. Evidence of the effect of increased age on the incidence of postoperative complications is varied. Aside from the generally increased risk following surgery in the elderly, age is unlikely to have a specific influence on the development of fistulae and other postoperative complications. ${ }^{2}$ In several studies that compared the operative outcome of selected patients aged 70-80 years or older with younger patients undergoing pancreatic resection, success was similar between the elderly and younger patients, as were mortality and overall morbidity rates. $^{1011}$

\section{PROPHYLACTIC THERAPY TO REDUCE POSTOPERATIVE COMPLICATIONS}

Based on an analysis of predisposing factors, the mechanism primarily responsible for postoperative complications following pancreatic surgery is the presence of proteolytic digestive enzymes. This risk factor is potentially controllable through inhibition of pancreatic exocrine secretion and in particular, reducing protease concentration. Studies in volunteers have demonstrated that pharmacotherapy with somatostatin-14 can have a significant impact on pancreatic protease secretion. ${ }^{12}{ }^{13}$ Klempa and colleagues ${ }^{14}$ first introduced the concept of inhibiting gastrointestinal secretion to reduce postoperative complications in 1979 in an uncontrolled trial with a limited number of patients. Preliminary data from this study suggested that continuous intravenous infusion of somatostatin-14, a potent inhibitor of gastrointestinal secretion, reduced the occurrence of postoperative complications when administered perioperatively in patients undergoing Whipple's procedure. ${ }^{14}$

\section{Somatostatin-14 and its analogues}

Somatostatin-14, a 14 amino acid hormone, is well established as a potent inhibitor of gastrointestinal secretion, inhibiting both endocrine and exocrine pancreatic secretion, and also secretion of various hormones, including cholecystokinin, vasoactive intestinal polypeptide, secretin, and gastrointestinal polypeptide. In addition, somatostatin-14 has been found to have additional regulatory effects in reducing gastrointestinal motility, gastric secretion, gall bladder emptying, and pancreatic blood flow. ${ }^{15-18}$ The physiological activity of somatostatin-14 may have a considerable impact in the prevention of pancreas related postoperative complications. Inhibition of gastrointestinal secretion will reduce both the volume of fluid secreted and the content of tissue destructive enzymes. In addition, reducing blood flow is likely to diminish the potential for serious haemorrhage, although this may be detrimental to healing following surgery. Somatostatin-14 also stimulates the reticuloendothelial system resulting in enhanced phagocytic activity, which may protect against sepsis. ${ }^{19}$

The synthetic somatostatin analogue octreotide is an octapeptide that was developed to extend the half life of the native hormone. The half life of octreotide has been increased to approximately 113 minutes after a single subcutaneous injection, ${ }^{17}$ compared with $1-2$ minutes for somatostatin- $14 .{ }^{18}$ Octreotide has a similar mode of action and clinical effects as somatostatin-14, mediated through interaction with somatostatin receptors (SSTRs) (reviewed by Jenkins ${ }^{19}$ and Lamberts and colleague ${ }^{20}$ ). To date, five SSTR subtypes have been identified, and while somatostatin-14 binds to all five with a high affinity, octreotide has little or no action on SSTR 1 and 4, a moderate effect on SSTR 3, and has only high binding affinity for SSTR subtypes 2 and $5 .{ }^{21-24}$ A study by Buscail and colleagues $^{25}$ has investigated somatostatin receptor subtype expression in normal human tissues or cell lines of pancreatic origin using reverse transcriptase-polymerase chain reaction. Heterogeneous expression of sstl, sst2, sst4, and sst5 was demonstrated; sst3 however was rarely or not expressed.

The prophylactic use of octreotide in the prevention of postoperative complications following pancreatic surgery has been investigated in a number of randomised, blinded, controlled, multicentre trials ${ }^{126-29}$ and also in one randomised open label trial. ${ }^{30}$ In contrast, there are considerably less data available regarding the use of somatostatin-14 in perioperative prophylactic treatment. This may be due to the prevailing opinion that on account of its extended half life, octreotide administered by subcutaneous injection three times daily is more convenient than a continuous somatostatin-14 infusion. There has to date been only one multicentre, randomised, placebo controlled trial that has assessed the efficacy of somatostatin-14 in the prevention of complications after Whipple's procedure. ${ }^{31}$

\section{Clinical experience with octreotide}

Four prospective, randomised, double blind, placebo controlled, multicentre trials have been performed using a similar protocol. ${ }^{16-28}$ Patients with malignant disease or chronic pancreatitis in whom abdominal surgery was required (pancreatic resection or pancreatic duct anastomosis) were randomly assigned to receive either octreotide $100 \mu \mathrm{g}$ three times daily or placebo, both administered one hour before surgery by subcutaneous injection and maintained for seven days. Definitions of postoperative complications were similar (although not identical) and are summarised in table 2; they are presented in detail elsewhere. ${ }^{1262734}$

The study of Büchler et al $(1992)^{26}$

This study recruited patients from 18 German centres, and subjects were stratified into two risk groups for the development of postoperative complications. As discussed previously, the underlying disease and pancreatic consistency 
Table 3 A review of prospective, randomised, double blind, multicentre trials investigating the use of the somatostatin analogue octreotide in the prevention of postoperative complications

\begin{tabular}{|c|c|c|c|c|c|c|c|c|}
\hline Trial & Groups & $\begin{array}{l}\text { Total } \\
\text { patients }\end{array}$ & $\begin{array}{l}\text { High risk } \\
\text { patients } \\
(n(\%))\end{array}$ & $\begin{array}{l}\text { Chronic } \\
\text { pancreatitis } \\
(\mathrm{n}(\%))\end{array}$ & $\begin{array}{l}\text { Whipple's } \\
\text { procedure } \\
\text { (n (\%)) }\end{array}$ & $\begin{array}{l}\text { Mortality } \\
\text { (n (\%)) }\end{array}$ & $\begin{array}{l}\text { Complication } \\
\text { rate } \\
(n(\%))\end{array}$ & $\begin{array}{l}\text { Pancreatic } \\
\text { fistula } \\
(\mathrm{n}(\%))\end{array}$ \\
\hline \multirow[t]{2}{*}{ Büchler et al $1992^{26}$} & Octreotide & 125 & 68 (54) & $57(46)$ & 73 (58) & $4(3)$ & $40(32)$ & $22(18)$ \\
\hline & Placebo & 121 & 71 (59) & $50(41)$ & $79(65)$ & $7(6)$ & 67 (55) & $46(38)$ \\
\hline \multirow[t]{2}{*}{ Pederzoli et al $1994^{1}$} & Octreotide & 122 & $76(62)$ & $46(38)$ & $50(41)$ & $2(2)$ & $19(16)$ & $11(9)$ \\
\hline & Placebo & 130 & $86(66)$ & 44 (34) & 50 (38) & $5(4)$ & 38 (29) & 24 (18) \\
\hline \multirow[t]{2}{*}{ Montorsi et al $1995^{27}$} & Octreotide & 111 & $98(91)$ & 8 (7) & 75 (68) & $9(8)$ & $24(22)^{*}$ & $10(9)^{*}$ \\
\hline & Placebo & 107 & 92 (91) & $10(9)$ & $66(62)$ & $6(6)$ & $39(36)$ & $21(20)$ \\
\hline \multirow[t]{2}{*}{ Friess et al $1995^{28}$} & Octreotide & 122 & 0 & $122(100)$ & $33(27)$ & $2(2)$ & 20 (16)‡‡ & $12(10)$ * \\
\hline & Placebo & 125 & 0 & $125(100)$ & $37(30)$ & $1(1)$ & $37(30)$ & $28(22)$ \\
\hline
\end{tabular}

ND, no data

†High risk patients include carcinoma and/or non-fibrotic pancreatic tissue, specifically excluding patients with chronic pancreatitis.

${ }^{*} p<0.05, \ddagger \neq p<0.007$

can influence the outcome of surgery. Patients with pancreatic or periampullary tumours (soft pancreas) were classified as high risk and patients with chronic pancreatitis (fibrotic pancreas) were classified as low risk. A total of 246 patients that met entry criteria were randomised to treatment groups (octreotide $n=125)$ and placebo $(n=121)$. Patients in both groups were well matched for age, sex, type of surgery, and underlying disease. The procedures performed included: Whipple's procedure $(61.8 \%)$, duodenum saving pancreatic head resection (19.5\%), left pancreatic resection (12.6\%), pancreaticojejunostomy $(3.3 \%)$, enucleation $(1.2 \%)$, and other $(1.6 \%)$.

The results of the study are summarised in table 3. Overall, mortality was $4.5 \%$ within the 90 day period following surgery, with no significant difference between the treatment groups. The most frequent complications reported were pancreatic fistulae (27.6\%), pulmonary insufficiency (11.4\%), bleeding (8.9\%), abscess (8.1\%), fluid collection (6.9\%), leakage of anastomosis $(5.3 \%)$, shock $(5.3 \%)$, sepsis $(3.7 \%)$, postoperative pancreatitis (1.6\%), and renal insufficiency (1.2\%). The overall complication rate and frequencies of pancreatic fistula, abscess, sepsis, pulmonary insufficiency, and postoperative pancreatitis were lower in the octreotide treated patients than those receiving placebo, as were serum pancreatic enzyme levels. In stratified risk groups the overall complication rate was significantly $(\mathrm{p}<0.01)$ reduced in high risk patients receiving octreotide in comparison with placebo $(38 \%$ $v 65 \%$ for octreotide and placebo, respectively). While a similar trend was observed in low risk patients, the difference in the overall complication rate did not reach significance. The incidence of fistula formation was reduced in the high risk patients $(24 \%$ in the octreotide group $v 41 \%$ in the placebo group) and in the overall patient population ( $18 \%$ in the octreotide group $v 38 \%$ in the placebo group). Octreotide was shown to be well tolerated and the incidence of minor side effects was comparable between the groups. The authors concluded that perioperative administration of octreotide reduces typical postoperative complications, and that the effects of treatment were most marked in high risk patients.

The study of Pederzoli et al (1994)

Patients with pancreatic or periampullary carcinoma, or chronic pancreatitis, were recruited from 20 Italian centres. As with the study of Büchler et al, subjects were stratified as high or low risk according to the underlying disease and consequent consistency of the pancreas. A total of 252 patients were randomised to treatment groups (octreotide $\mathrm{n}=122$ ) and placebo $(n=130)$. Patients in both groups were homogeneous for age, sex, type of surgery, and underlying disease. The procedures performed included: Whipple's procedure $(39.7 \%)$, pancreaticojejunostomy $(26.2 \%)$, left pancreatic resection $(23.8 \%)$, enucleation $(5.6 \%)$, intermediate resection $(2.8 \%)$, and duodenum saving pancreatic head resection $(2 \%)$.

Overall mortality was $2.8 \%$ within a postoperative period of 90 days and no significant difference between the treatment groups was noted (table 3). Overall, the frequency of complications was significantly lower in octreotide treated patients than those receiving placebo $(\mathrm{p}<0.01)$ and the incidence of fistula formation was reduced ( $9 \%$ in the octreotide group $v$ $18 \%$ in the placebo group). However, somewhat surprisingly and in contrast with the findings of Büchler and colleagues, ${ }^{26}$ the general trend towards the reduction in complications only

Table 2 A summary of the definitions of complications associated with pancreatic leakage in the double blind, multicentre, placebo controlled trials with octreotide

Definition of leakage related complications

\begin{tabular}{|c|c|c|c|}
\hline $\begin{array}{l}\text { Trial } \\
\text { Büchler et al } 1992^{26}\end{array}$ & $\begin{array}{l}\text { Pancreatic fistula } \\
\text { Concentration of amylase and lipase in the } \\
\text { drainage fluid }>3 \text { days postoperatively of } \\
>3 \text { times the normal serum value and a } \\
\text { drainage volume of }>10 \mathrm{ml} / 24 \text { hours }\end{array}$ & $\begin{array}{l}\text { Abdominal abscess } \\
\text { Collection of pus or infected fluid confirmed by } \\
\text { ultrasound or CT guided aspiration and } \\
\text { culture, or second laparotomy }\end{array}$ & $\begin{array}{l}\text { Intra-abdominal fluid collection } \\
\text { Fluid collection (sterile) of at least } \\
5 \times 5 \mathrm{~cm} \text { in diameter by ultrasound } \\
\text { or } \mathrm{CT}\end{array}$ \\
\hline Pederzoli et al 1994' & $\begin{array}{l}\text { Drain output with amylase content }>3 \text { times } \\
\text { the maximum normal value exceeding } 10 \\
\mathrm{ml} / 24 \text { hours for } \geqslant 4 \text { days from day } 4 \text { after } \\
\text { the operation }\end{array}$ & $\begin{array}{l}\text { Collection of pus or infected fluid confirmed by } \\
\text { ultrasound or CT guided aspiration and } \\
\text { culture, or second laparotomy }\end{array}$ & $\begin{array}{l}\text { Fluid collection (sterile) of at least } \\
5 \times 5 \mathrm{~cm} \text { in diameter by ultrasound } \\
\text { or } \mathrm{CT}\end{array}$ \\
\hline Montorsi et al $1995^{27}$ & $\begin{array}{l}\text { Concentration of amylase and lipase in the } \\
\text { drainage fluid }>3 \text { days postoperatively of } \\
>3 \text { times the normal serum value and a } \\
\text { drainage volume of }>10 \mathrm{ml} / 24 \text { hours }\end{array}$ & $\begin{array}{l}\text { Collection of infected fluid with normal } \\
\text { amylase concentration, with or without pus, } \\
\text { confirmed by ultrasound or CT guided } \\
\text { aspiration and culture, or second laparotomy }\end{array}$ & $\begin{array}{l}\text { An intraperitoneal sac containing } \\
\text { sterile fluid, with or without } \\
\text { amylase }\end{array}$ \\
\hline Friess et al $1995^{28}$ & $\begin{array}{l}\text { Complications were defined and recorded } \\
\text { as previously reported } 293536\end{array}$ & & \\
\hline
\end{tabular}

$\mathrm{CT}$, computed tomography. 
Table 4 Other trials with octreotide for the prevention of postoperative complications

\begin{tabular}{|c|c|c|c|c|c|c|c|c|}
\hline Trial & Design & Groups & $\begin{array}{l}\text { Total } \\
\text { patients }\end{array}$ & $\begin{array}{l}\text { High risk } \\
\text { patients } \\
\mathrm{n}(\%))\end{array}$ & $\begin{array}{l}\text { Chronic } \\
\text { pancreatitis } \\
\text { (n (\%)) }\end{array}$ & $\begin{array}{l}\text { Mortality } \\
\text { (n (\%)) }\end{array}$ & $\begin{array}{l}\text { Complication } \\
\text { rate }(\mathrm{n}(\%))\end{array}$ & $\begin{array}{l}\text { Pancreatic } \\
\text { fistulae } \\
\text { (n (\%)) }\end{array}$ \\
\hline \multirow[t]{2}{*}{ ARC-AURC $1997^{29}$} & \multirow{2}{*}{$\begin{array}{l}\text { Double blind, } \\
\text { multicentre }\end{array}$} & Octreotide & 122 & 48 (39) & & \multirow[t]{2}{*}{$12(10)$} & $27(22)^{*}$ & 21 (17) \\
\hline & & No treatment & 108 & 53 (49) & 27 & & 35 (32) & $20(18.5)$ \\
\hline \multirow[t]{2}{*}{ Lowy et al $1997^{30}$} & \multirow{2}{*}{$\begin{array}{l}\text { Open, single } \\
\text { institution }\end{array}$} & Octreotide & 57 & 56 (98) & $1(2) \ddagger$ & $1(2)$ & $17(30)$ & $7(12)$ \\
\hline & & No treatment & 53 & 49 (92) & $4(8) \ddagger$ & 0 & $13(25)$ & $3(6)$ \\
\hline
\end{tabular}

reached significance in low risk patients $(\mathrm{p}<0.05)$. The most frequent complications reported in the octreotide and placebo groups, respectively, were pancreatic fistulae (9\% v 18\%), fluid collection $(6.6 \% \vee 10 \%)$, sepsis $(1.6 \% \vee 6.1 \%)$, leakage of anastomosis $(3.3 \% \vee 3.8 \%)$, and abscess $(2.5 \% \vee 4.6 \%)$. Octreotide was generally well tolerated, although moderate to severe side effects were reported in four patients following octreotide treatment, leading to withdrawal of therapy in one case due to febrile rash. In conclusion, the authors stated that octreotide reduced the complications associated with elective pancreatic surgery.

\section{The study of Montorsi et al $(1995)^{27}$}

This multicentre trial enrolled 278 patients: 54 were dropped from the study-50 due to the presence of advanced neoplastic disease requiring palliative surgery and four requiring total pancreatectomy. Histological findings of resected specimens revealed a majority of pancreatic and periampullary carcinomas $(64.3 \%)$. Abdominal neoplasms $(17.1 \%)$, chronic pancreatitis $(8 \%)$, endocrine tumours $(6.5 \%)$, and miscellaneous conditions $(3.7 \%)$ accounted for the remainder of the patients. As the proportion of patients with chronic pancreatitis was relatively low, no risk stratification was performed. A total of 218 patients were randomised to treatment groups (octreotide $\mathrm{n}=111)$ and placebo $(\mathrm{n}=107)$. Patients in both groups were comparable for age, sex, type of surgery, and underlying disease. The procedures performed included: Whipple's procedure $(39.9 \%)$, duodenum saving pancreatic head resection $(25.7 \%)$, left pancreatic resection $(24.8 \%)$, subtotal pancreatectomy (5.5\%), enucleation (2.3\%), and other (1.8\%).

The results of the study are summarised in table 3. Overall mortality was $6.9 \%$ within a postoperative period of 60 days, with no significant difference between treatment groups. The frequency of both global complications and pancreatic fistula formation was significantly reduced in the octreotide treatment group in comparison with those receiving placebo $(\mathrm{p}<0.05)$. The most frequent complications reported in the octreotide and placebo groups, respectively, were pancreatic fistulae $(9 \% \vee 20 \%)$, bleeding $(7.2 \% \vee 8.4 \%)$, anastomosis leakage $(2.7 \% \vee 8.4 \%)$, fluid collection ( $1.8 \% \vee 8.4 \%)$, and abscess $(3.6 \% v 2.8 \%)$. Again, octreotide was generally well tolerated, with a low incidence of side effects $(2.8 \%)$ evenly distributed between the two treatment groups. The authors concluded that octreotide was able to reduce the incidence of pancreatic fistulae and other stump related complications to a statistically significant degree.

\section{The study of Friess et al $(1995)^{28}$}

In contrast with the trials described previously, this study focused on the low risk population and only patients with chronic pancreatitis requiring pancreatic resection or pancreatic duct anastomosis were recruited. A total of 247 subjects from 19 surgical departments in Germany were evaluated and randomised for treatment (octreotide $n=122$ ) and placebo $(n=125)$. Patients in both groups were matched for age, sex, type of surgery, and underlying disease. The procedures performed included: Whipple's procedure $(28 \%)$, pancreaticojejunostomy $(25 \%)$, left pancreatic resection $(22 \%)$, duodenum saving pancreatic head resection $(22 \%)$, and other $(3 \%)$.

Overall mortality was $1.2 \%$ within the 90 day period following surgery, with no significant difference between the treatment groups (table 3 ). The overall complication rate was significantly reduced following octreotide treatment compared with placebo $(16.4 \%$ v $29.6 \%$; $\mathrm{p}<0.007)$. The most frequent complications reported in the octreotide and placebo groups, respectively, were pancreatic fistulae $(9.8 \% \vee 22.4 \%)$, fluid collection ( $3 \% v 9.6 \%)$, pulmonary insufficiency $(6.5 \% v$ $2.4 \%)$, and bleeding $(5.7 \% \vee 3.2 \%)$. In this study, the reduction in fistula formation and fluid accumulation reached statistical significance $(p<0.05)$. Octreotide was shown to be well tolerated and the incidence of minor side effects was comparable between groups. This study demonstrated that when used perioperatively, octreotide substantially reduced the risk of postoperative complications following major surgery for chronic pancreatitis.

\section{The study of ARC-AURC (1997) 29}

This multicentre, prospective, randomised, controlled trial was conducted in France and recruited 230 patients from 21 institutions. However, this study has only been published as an abstract and details of the study protocol and design are limited. Patients were stratified according to the degree of pancreatic fibrosis, as high risk (non-fibrotic) and low risk (fibrotic). Following randomisation, 122 patients received octreotide $100 \mu \mathrm{g}$ three times daily for 10 days, initiated prior to surgery, and 108 received no octreotide. These two groups were homogeneous for underlying pathology, pancreatic consistency, and type of anastomosis performed. The surgery performed was: pancreaticoduodenectomy $(77 \%)$ and splenopancreatic resection $(23 \%)$.

The results are summarised in table 4. Overall mortality was $10 \%$ with no significant difference between treatment groups. The consistency of the pancreatic tissue was found to have a significant effect on the rate of fistula formation; $35 \%$ in the non-fibrotic versus $14 \%$ in fibrotic pancreas $(p<0.01)$. The overall complication rate in high risk patients following surgery was reduced in the octreotide treatment group following both Whipple's procedure $(17 \% v 45 \%$; $\mathrm{p}<0.04)$ and pancreaticojejunostomy $(24 \% v 41 \% ; \mathrm{p}<0.06)$. In patients with soft pancreatic tissue undergoing Whipple's resection, the incidence of pancreatic fistulae in patients receiving octreotide was reduced ( $12 \%$ in the octreotide group $v 28.5 \%$ in the control group) but not to a significant degree $(p<0.07)$. In conclusion, it was stated that octreotide may benefit patients with a non-fibrotic pancreas undergoing Whipple's procedure, by reducing the risk of postoperative complications.

The single institution, open study of Lowy et al $(1997)^{30}$ This study included subjects with pancreatic or periampullary carcinoma, and confirmed cases of chronic pancreatitis were excluded. Fewer patients were recruited than in the previous trials; 110 in total, randomised to receive octreotide $(n=57)$ or 
no treatment $(n=53)$. Patients in both groups were homogeneous for age, sex, type of surgery, and underlying disease. All patients received pancreaticoduodenectomy including distal gastrectomy, and pylorus preservation was not performed. In contrast with the other studies, patients received octreotide $150 \mu \mathrm{g}$ for five days (rather than $100 \mu \mathrm{g}$ three times daily for seven days). Furthermore, preoperative chemoradiation was administered to $46 \%$ and $38 \%$ of octreotide treated and control groups, respectively; and intraoperative electron beam radiation therapy was administered in $60 \%$ and $57 \%$, respectively. In addition, administration of study drug was not initiated until immediately after surgery or on arrival in surgical intensive care. Patients were only followed up to the 30th postoperative day, rather than over a longer period (60-90 days), as described in previous trials. ${ }^{16-28}$ Lowy et al also utilised different definitions; pancreatic anastomotic leak was classified as drainage of amylase rich fluid (concentration $>2.5$ times the upper limit of normal for serum amylase) in association with fever $\left(>38^{\circ} \mathrm{C}\right)$, leucocytosis (white blood cell count $>10000 / 1)$, sepsis, or the need for percutaneous drainage of amylase rich fluid. A biochemical anastomotic leak was defined as an elevated level of amylase (concentration $>2.5$ times the upper limit of normal for serum amylase) in the drain fluid on or after the third postoperative day that was asymptomatic and resolved spontaneously.

The results of the study are summarised in table 4 . One patient in the octreotide group died during the trial. The frequency of global complications (octreotide 30\% v control $25 \%$ ) and the rate of fistula formation (octreotide $12 \% v$ control $6 \%$ ) were comparable in both groups, although slightly elevated in the octreotide group in both cases. In addition, no significant reduction in the period of hospitalisation was noted. Octreotide was generally well tolerated, although $11 \%$ of octreotide treated patients required greater than 21 days in hospital postoperatively due to delayed return of gastrointestinal function, manifested as poor gastric emptying and intolerance to enteral nutrition. In conclusion, it was stated that octreotide conveyed no benefit in preventing anastomotic leakage after Whipple's procedure.

\section{Critical analysis of the octreotide studies}

The rationale behind the use of somatostatin-14 or its analogue octreotide to prevent postoperative complications following pancreatic surgery is based on an ability to reduce pancreatic and other gastrointestinal secretions. Multicentre, prospective, double blind, randomised trials ${ }^{126-29}$ all revealed that octreotide has the ability to significantly reduce the overall complication rate following surgery. While these results appear promising, aspects of design and interpretation of the findings of these studies are open to criticism.

From a methodological viewpoint, all postoperative complications were included and analysed together, without comment as to their clinical relevance and possible association with pancreatic and anastomosis leakage. While these five studies all reported that octreotide treatment reduced the postoperative complication rate, surprisingly, given the mechanism of action, the benefit appeared less obvious when events associated with pancreatic secretion were considered in isolation. Indeed, while each trial revealed a decrease in the incidence of pancreatic fistulae, the reduction was only reported as significant in the studies by Montorsi and colleagues $^{27}(9 \%$ octreotide $v 19.6 \%$ placebo; $\mathrm{p}<0.05)$ and Friess and colleagues ${ }^{28}(9.8 \%$ octreotide $v 22.4 \%$ placebo; $\mathrm{p}<0.05)$. However, in the studies by Büchler and colleagues ${ }^{26}$ and Pederzoli and colleagues, ${ }^{1}$ this analysis was not included in the trial design, although in both cases the data appeared to represent a change of significant magnitude. No significant reduction in mortality was demonstrated following treatment with octreotide although it should be noted that mortality was low in all of the placebo groups $(0.4-10 \%)$.
A further potential methodological disadvantage that may be accentuated in multicentre trials is inclusion of many surgeons performing several different types of procedures. Previous logical regression studies have clearly demonstrated that the experience of the surgeon performing Whipple's procedure is associated with fewer pancreatic fistulae. ${ }^{25}$ This issue was addressed by Lowy and colleagues ${ }^{30}$ who used a standardised technique and Montorsi and colleagues ${ }^{27}$ who adopted a single reconstruction technique after resection, reducing the potential for bias. Furthermore, the latter authors pointed out that the trial by Büchler and colleagues ${ }^{26}$ included the use of a polymeric resin in $16 \%$ of the patient population, which has been associated with a higher rate of fistula formation.

The majority of studies accounted for the effect of pancreatic morphology by either excluding patients with chronic pancreatitis or stratifying patients according to risk; malignant disease as high risk and chronic pancreatitis as low risk. ${ }^{12629}$ Stratification was not performed in the trial of Montorsi and colleagues ${ }^{27}$ but chronic pancreatitis patients represented a small proportion of the overall study population. Friess and colleagues ${ }^{28}$ however focused on the low risk group, only recruiting patients with chronic pancreatitis. In view of the patient population under investigation, it is somewhat surprising that the reported incidence of fistula formation was as high as $22 \%$ in the placebo group of this study. Büchler and colleagues $^{26}$ demonstrated that the effect of octreotide treatment was most marked in the high risk group in which a significant reduction in the overall complication rate was observed $(\mathrm{p}<0.01)$ while the reduction in low risk patients was not significant. In contrast, Pederzoli and colleagues ${ }^{1}$ revealed a general trend towards reduction in complications that reached significance only in low risk patients $(\mathrm{p}<0.05)$. These authors noted that in both series, the sample size of each stratification group (approximately 100 patients) was approximately half the number of patients required to detect a $40 \%$ difference between treatments. Consequently, they recommend caution in interpretation of data with regard to the importance of risk stratification on the efficacy of octreotide. ${ }^{1}$

The overall rate of pancreatic fistula in these trials was higher than rates documented elsewhere of approximately $6 \%{ }^{30}{ }^{35}$ Moreover, it has been stated that the high incidence of pancreatic fistulae in placebo groups increases the apparent efficacy of octreotide treatment. ${ }^{36}$ However, differences in the observed rate of fistula formation are likely to reflect variations in the definitions and clinical end points used, and may also be due to differences in surgical experience and the quality of the suture. Single centre studies from "expert" institutions often have markedly lower complication rates than those reported in multicentre studies where the institutions involved perform far fewer operations annually. However, in general, multicentre studies are a more accurate reflection of clinical practice.

The recent open study from a single expert institution in the USA $^{30}$ revealed contrasting results to those of multicentre, double blind, placebo controlled studies conducted in Europe. This trial found no significant benefits in patients administered octreotide therapy following Whipple's procedure. Moreover, the rate of pancreatic fistula development was actually found to increase in patients administered octreotide in comparison with no treatment, although the increase was not significant. It is important to note however that marked differences in study design may account for the widely differing outcome in this trial.

The principal difference between this trial ${ }^{30}$ and previous studies is that the study drug was not administered until after surgery. The use of somatostatin-14 and octreotide to prevent postoperative complications relies on inhibition of pancreatic exocrine secretion prior to surgery, to limit the likelihood of pancreatic anastomosis failure. ${ }^{34}$ However, the treatment still constituted prophylactic pharmacotherapy as octreotide was administered prior to the onset of complications. In the previous European trials, octreotide was administered one hour 
Table 5 Prospective, randomised, multicentre, double-blind trial with somatostatin-14 in the prevention of postoperative complications

\begin{tabular}{|c|c|c|c|c|c|c|c|c|}
\hline Study & Groups & $\begin{array}{l}\text { Total } \\
\text { patients }\end{array}$ & $\begin{array}{l}\text { High risk } \\
\text { patients† (\%) }\end{array}$ & $\begin{array}{l}\text { Mean hospital } \\
\text { stay (days) }\end{array}$ & $\begin{array}{l}\text { Chronic } \\
\text { pancreatitis (\%) }\end{array}$ & $\begin{array}{l}\text { Mortality } \\
(\%)\end{array}$ & $\begin{array}{l}\text { Complication } \\
\text { rate (\%) }\end{array}$ & $\begin{array}{l}\text { Pancreatic } \\
\text { fistula (\%) }\end{array}$ \\
\hline \multirow[t]{2}{*}{ Gouillat et al $1998^{31}$} & Somatostatin-14 & 38 & 100 & $18 *$ & 0 & 5 & 21 & $5^{*}$ \\
\hline & Placebo & 37 & 92 & 26 & 10 & 3 & 35 & 22 \\
\hline
\end{tabular}

†High risk patients include non-fibrotic pancreatic tissue.

${ }^{*} \mathrm{p}<0.05$.

before surgery to allow downregulation of digestive secretions. ${ }^{26-28}$ In addition, the open design of the American study $^{30}$ increases the potential for bias, which represents a considerable disadvantage compared with a double blind trial design. It is well known that bias of investigators can have a marked impact on study findings. ${ }^{34}$

The European trials addressed the issue of pancreatic consistency as a risk factor for postoperative complications through stratification of patients with malignant disease and chronic pancreatitis, or selective exclusion of either neoplasms or pancreatitis. While the Lowy trial ${ }^{30}$ only recruited patients with cancer (high risk patients according to the collective criteria of the European studies), administration of radiotherapy could have altered the texture of the pancreas and simultaneously reduced the ability for exocrine secretion. As a consequence, the patient population may have potentially fulfilled the low risk stratification parameters where greater patient numbers are required to demonstrate efficacy. ${ }^{34}$

In summary, octreotide appears, overall, to convey a significant advantage in the prevention of postoperative complications following pancreatic surgery. Furthermore, a recent meta-analysis revealed that octreotide treatment reduced the overall cost of treatment in patients at risk of developing complications. ${ }^{4}$ However, even when the complication rate was reduced, in the majority of studies octreotide failed to demonstrate a significant reduction in the occurrence of pancreatic fistulae. To date, the efficacy of octreotide has been assessed in varied conditions that include differences in underlying disease and malignancy type, consistency of the pancreas, type of surgery, skill and experience of the surgical team, definitions of end points, and dosing schedules. While the results appear to be promising, a significant clinical advantage for the use of octreotide in the prevention of pancreas related events has yet to emerge following major pancreatic surgery.

\section{Experience with somatostatin-14 in the reduction of postoperative complications}

In comparison with octreotide, data regarding the prophylactic use of somatostatin-14 are limited.

The study of Gouillat et al $(2001)^{31}$

To date, this is the only prospective, multicentre, randomised, double blind, placebo controlled study to assess the efficacy of somatostatin-14 on pancreatic remnant secretions after pancreaticoduodenectomy, including clinical evaluation with special regard to pancreas related complications. The study recruited 75 patients requiring pancreatic resection for malignancy, with no evidence of chronic pancreatitis. Subjects were randomised to receive a continuous infusion of somatostatin-14 (6 mg/24 hours for six days and $3 \mathrm{mg} / 24$ hours on day 7 ) or placebo $(n=38$ and $n=37$, respectively) immediately after surgery. Patients in both groups were matched for age, sex, anastomotic technique, and underlying disease.

The results of the study are summarised in table 5. Overall mortality was $5 \%$ in the somatostatin-14 group and 3\% in the placebo group in the one month period following surgery, although the difference between the treatment groups was not significant. In this study, complications were classified as "fistula", "stump related", "other", and "total" postoperative complications. A trend towards a decrease in the total complication rate was noted in the somatostatin-14 group although this was not statistically significant. However, when classified according to relevance to pancreatic secretion, significant reductions in pancreatic fistula $(5 \% \vee 22 \% ; \mathrm{p}=0.037)$ and stump related complications were observed (13\% v 32\%; $\mathrm{p}=0.046$ ) in somatostatin-14 treated patients compared with placebo. Data from biochemical evaluations performed on both pancreatic juice and peripancreatic drainage led the authors to suggest that somatostatin-14 infusion after Whipple's procedure decreases leakage of pancreatic enzymes from the remnant, with a consequent reduction in pancreas related complications.

The findings of the study of Gouillat et al support data from a number of small open label trials with somatostatin-14 in patients with underlying disease of mixed aetiology. In one randomised study in 35 patients, somatostatin-14 prophylaxis significantly reduced pancreatic anastomosis failure following Whipple's procedure in comparison with no treatment $(10 \% \mathrm{v}$ $36 \%$, respectively; $\mathrm{p}<0.05$ ). However, no correlation between prophylaxis and other complications or postoperative mortality was demonstrated. ${ }^{37}$ A further non-randomised study in 34 patients demonstrated marked reductions in complications and mortality following pancreatic resection for malignant disease and chronic pancreatitis in somatostatin-14 treated patients compared with no prophylactic therapy $(50 \%$ morbidity, $5.5 \%$ mortality $v \quad 68.7 \%$ morbidity, $31.2 \%$ mortality). ${ }^{38}$ However, due to limited patient numbers, no statistical significance could be established.

\section{CONCLUSIONS}

The rationale behind the need for prophylactic treatment with pancreatic surgery is based on the fact that due to the anatomy and physiology of the pancreas, postoperative complications are common. Moreover, pancreatic fistulae-often the most frequent and serious of the potential sequelae-require prolonged treatment once established, with considerable impact on both quality of life and treatment cost. Pancreatic fistulae occur most frequently following Whipple's procedure to resect malignant disease, and thus it is these patients who stand to benefit most from prophylactic measures. The weight of evidence currently suggests that prophylaxis in surgical cases where significant exocrine secretion may be expected can reduce the occurrence of postoperative complications and, consequently, be of benefit to the patient. Octreotide, for which the majority of data are available, conveys a significant reduction in the overall complication rate, although with respect to pancreas related events such as fistula formation, the benefit has been less conclusive.

Preliminary studies with somatostatin-14 have to date demonstrated a significant reduction in fistula formation and secretion related events, although in the absence of a large body of experimental evidence, specific advantages remain largely theoretical. It is conceivable that as a continuous infusion, therapeutic serum concentrations of somatostatin-14 may be rapidly achieved and reliably maintained. Indeed, there are data suggesting that octreotide treatment may be associated with clinically relevant troughs in serum concentrations leading to loss of enzyme inhibitory activity. ${ }^{39}$ The 
potential implications of such fluctuations have been discussed in depth elsewhere in this supplement (Hesse and de Hemptinne, this supplement, page ivll). In addition, the increased half life of octreotide is considered beneficial as it facilitates subcutaneous administration. However, as the majority of these patients will be receiving intravenous medication, intravenous access will already be provided. Administration of somatostatin-14 by continuous infusion via an existing access will also reduce the number of potentially painful injections required. Early results with both somatostatin-14 and its analogues warrant further study in large scale well controlled trials to establish specific benefits, particularly in high risk patients who undergo Whipple's procedure for malignant disease.

\section{Authors' affiliations}

C Gouillat, Department of Chirurgie, Hôtel Dieu, 1 Place de l'Hôpital, 69288 Lyon Cedex 02, France

J-F Gigot, Chirugie Hépato-bilio- pancréatique, Cliniques Universitaires Saint-Luc, Avenue Hippocrate 10/1400, 1200 Brussels, Belgium

\section{REFERENCES}

1 Pederzoli P, Bassi C, Falconi $M$, et al. Efficacy of octreotide in the prevention of complications of elective pancreatic surgery. Br J Surg 1994:81:265-9.

2 Bartoli FG, Arnone GB, Ravera G, et al. Pancreatic fistula and relative mortality in malignant disease after pancreaticoduodenectomy. Review and statistical meta-analysis regarding 15 years of literature. Anticancer Res 1991;11:1831-48.

3 Friess $\mathbf{H}$, Müller MW, Büchler MW. Duodenum-preserving pancreatic head resection: the future. Dig Surg 1994;1:318-24.

4 Rosenberg L, MacNeil P, Turcotte L. Economic evaluation of the use of octreotide for prevention of complications following pancreatic resection. J Gastrointest Surg 1999;3:225-32.

5 Trede M, Schwall G. The complications of pancreatectomy. Ann Surg 1988;207:39-47.

6 Van Berge Henegouwen MI, Van Gulik TM, Obertop H, et al. Incidence, risk factors, and treatment of pancreatic leakage after pancreaticoduodenectomy: drainage versus resection of the pancreatric remnant. Surgery 1996;119:281-7.

7 Hamanaka Y, Nishihara K, Hamasaki T. Pancreatic juice output after pancreatoduodenectomy in relation to pancreatic consistency, duct size, and leakage. Surgery 1996; 119:281-7.

8 Bradley EL III. Complications of chronic pancreatitis. Surg Clin North Am 1989;69:481-97.

9 Forrest JF, Longmire WP Jr. Carcinoma of the pancreas and periampullary region. Ann Surg 1979;189:129-38.

10 DiCarlo V, Balzano G, Zerbi A, et al. Pancreatic cancer resection in elderly patients. Br J Surg 1998;85:607-10.

11 Sohn TA, Yeo CJ, Cameron JL, et al. Should pancreaticoduodenectomy be performed in octogenarians? J Gastrointest Surg 1998;2:207-16.

12 Gullo L, Priori P, Scarpignato C, et al. Effect of somatostatin 14 on pure human pancreatic secretion. Dig Dis Sci 1987;32:1065-70.

13 Vatn $\mathbf{M H}$, Schrumpf E, Hanssen KF, et al. A small dose of somatostatin inhibits the secretin stimulated secretion of bicarbonate, amylase, and chymotrypsin in man. J Endocrinol Invest 1980;3:279-82.

14 Klempa I, Schwedes U, Usadel KH. Verhütung von postoperativen pankreatitischen Komplikationen nach Duodenopankreatektomie durch Somastostatin. Chirurg 1979;50:427-31.

15 Reichlin S. Somatostatin (two parts). N Engl J Med 1983;309:1495$501,1556-63$
16 Heintges T, Luthen R, Niederau C. Inhibition of exocrine pancreatic secretion by somatostatin and its analogues. Digestion 1994;55(suppl 1): 1-9

17 Kutz K, Nuesch E, Rosenthaler J. Pharmacokinetics of SMS 201-995 in healthy subjects. Scand J Gastroenterol 1986;21 (suppl 119):65-72.

18 Sheppard M, Shapiro B, Pimstone B, et al. Metabolic clearance and plasma half-disappearance time of exogenous somatostatin in man. J Clin Endocrinol Metab 1979;48:50-3.

19 Jenkins SA. Emerging differences in the therapeutic efficacy of somatostatin and octreotide in gastroenterology and surgery. Hong Kong: MediMedia, 1996:14-16.

20 Lamberts SWJ, van der Lely A-J, de Herder WW, et al. Octreotide. N Engl J Med 1996:334:246-54.

21 Patel YC, Greenwoood MT, Warszynska A, et al. All five cloned human somatostatin receptors (hSSTR 1-5) are functionally coupled to adenylate cyclase. Biochem Biophys Res Commun 1994;198:605-12.

22 Patel YC, Srikant CB. Subtype selectivity of peptide analoges for all five cloned human somatostatin receptors (hsstr 1-5). Endocrinology 1994; 135:2814-7.

23 Bruns C, Weckbecker G, Raulf F, et al. Molecular pharmacology of somatostatin-receptor subtypes. Ann N Y Acad Sci 1994;733:138-46.

24 Kubota A, Yamada Y, Kagimoto S, et al. Identification of somatostatin receptor subtypes and an implication for the efficacy of somatostatin analogue SMS 201-995 in treatment of human endocrine tumors. J Clin Invest 1994;93:1321-5.

25 Buscail L, Saint-Laurent N, Chastre E, et al. Loss of sst2 somatostatin receptor gene expression in human pancreatic and colorectal cancer. Cancer Res 1996;56:1823-7

26 Büchler M, Friess H, Klempa I, et al. Role of octreotide in the prevention of postoperative complications following pancreatic resection. Am J Surg 1992;163:125-36.

27 Montorsi M, Zago M, Mosca F, et al. Efficacy of octreotide in the prevention of pancreatic fistula after elective pancreatic resections: a prospective, controlled, randomized clinical trial. Surgery $1995 ; 117: 26-31$

28 Friess H, Beger HG, Sulkowski U, et al. Randomized controlled multicentre study of the prevention of complications by octreotide in patients undergoing surgery for chronic pancreatitis. Br J Surg $1995: 82: 1270-3$

29 Associations de Recherche en Chirurgie-ARC, AURC, Fourtanier G. Intérêt de l'octréotide dans la prevention des complications chirurgicales post-opératoires après pancréatectomie-étude prospective randomisée multicentrique. Gastroenterol Clin Biol 1997;21:A64.

30 Lowy AM, Lee JE, Pisters PWT, et al. Prospective, randomized trial of octreotide to prevent pancreatic fistula after pancreaticoduodenectomy for malignant disease. Ann Surg 1997;226:632-41

31 Gouillat C, Chipponi J, Baulieux S, et al. A randomised controlled multicentre trial of somatostatin infusion after pancreaticoduodenectomy. $\mathrm{Br} J$ Surg 2001;88: 1-8.

32 Büchler $M$, Friess $H$. Prevention of postoperative complications following pancreatic surgery. Digestion 1993:54(suppl 1):41-6.

33 Büchler M, Friess $H$. Inhibition of pancreatic secretion to prevent postoperative complications following pancreatic resection. Acta Gastroenterol Belg 1993;56:271-8.

34 Berberat PO, Friess $\mathrm{H}$, Uhl W, et al. The role of octreotide in the prevention of complications following pancreatic resection. Digestion 1999;60(suppl 2):15-22.

35 Yeo CJ, Cameron JL, Maher MM, et al. A prospective randomized trial of pancreaticogastrostomy versus pancreaticojejunostomy after pancreaticoduodenectomy. Ann Surg 1995;222:580-92

36 Yeo CJ. Does prophylactic octreotide benefit patients undergoing elective pancreatic resection? J Gastrointest Surg 1999;3:223-4.

37 Beguiristain A, Espí A, Balen E, et al. Profilaxis con Somatostatina tras duodenopancreatectomía cefálica. Rev Esp Enferm Dig 1995;87:221-4

38 Van Hee R, De Laet I, Salgado R, et al. The influence of somatostatin on postoperative outcome after elective pancreatic surgery. Acta Chir Belg 1998;98:625.

39 Jenkins AS, Nott DM, Baxter JN. Fluctuations in the secretion of pancreatic enzymes between consecutive doses of octreotide: implications for the management of fistulae. Eur J Gastroenterol Hepatol $1995 ; 7: 255-8$. 